F.J. DUARTE

\title{
Multiple-prism dispersion equations for positive and negative refraction
}

Interferometric Optics, P.O. Box 26592, Rochester, NY 14626, USA

Published online: 28 July 2006 • ㄷ Springer-Verlag 2006

In a recent paper by Duarte [1] the sentence following (8) which now reads: "The same outcome is obtained for the case of incidence below the normal and refraction below the normal" should read "The same outcome is obtained for the case of incidence above the normal and refraction below the normal."

\section{REFERENCE}

1 F.J. Duarte, Appl. Phys. B 82, 35 (2006)
Appl. Phys. B 82, 35 (2006)

DOI 10.1007/s00340-005-1996-x

Published online: 17 November 2005 